\title{
Vivências de cuidadores familiares de pessoas portadoras da doença de Alzheimer ${ }^{1}$
}

\author{
Ana Janete Backes*; Cleci Lourdes Schmidt Piovesan Rosanelli"; Leila Mariza Hildebrandt"*;

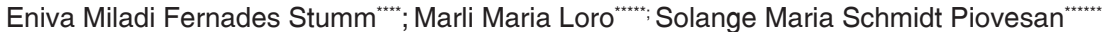

\section{Resumo}

A doença de Alzheimer pode ser considerada uma doença familiar por interferir no cotidiano das famílias. A pesquisa busca conhecer vivências de familiares cuidadores de pessoas com doença de Alzheimer. É qualitativa, descritiva, compreendendo seis familiares/cuidadores que mantinham convívio direto com os doentes, residentes em quatro municípios da região Noroeste do Rio Grande do Sul. A coleta de dados ocorreu em novembro de 2006, mediante entrevista aberta, com a seguinte questão norteadora: "Como é/foi para você cuidar de seu familiar com doença de Alzheimer?" A análise dos dados seguiu os passos preconizados para análise temática e os aspectos éticos que envolvem pesquisas com pessoas foram observados. Da análise dos depoimentos emergiu o tema: "vivên- cias de familiares cuidadores de pessoas com doença de Alzheimer: o impacto da enfermidade no cotidiano da família." Eles expressaram dificuldades no manejo do paciente, desconhecimento da doença, tristeza e insegurança. Identifica-se a necessidade de assistência domiciliária por profissionais da saúde aos familiares cuidadores de pessoas com Alzheimer, incluindo orientações e suporte referentes à enfermidade e aos cuidados necessários. Os resultados desta pesquisa mostram também que os familiares não são elemento de intervenção das equipes de saúde e que as ações são fragmentadas e pontuais.

Palavras-chave: Envelhecimento. Doença de Alzheimer. Cuidadores. Relações familiares.

* Enfermeira graduada no curso de Enfermagem da Universidade Regional do Noroeste do Estado do Rio Grande do Sul.

* Enfermeira. Mestra em Educação nas Ciências pela Universidade Regional do Noroeste do Estado do Rio Grande do Sul. Professora do Departamento de Ciências da Saúde da Universidade Regional do Noroeste do Estado do Rio Grande do Sul. Endereço para correspondência: Cleci Piovesan Rosanelli, Universidade Regional do Estado do Rio Grande do Sul, Rua São Boaventura, 37, Bairro São Geraldo, CEP 98700-000, Ijuí - RS. E-mail: cleci.rosanelli@unijui.edu.br

**** Enfermeira. Mestra em Enfermagem Psiquiátrica pela Universidade de São Paulo. Professora do Departamento de Ciências da Saúde da Universidade Regional do Noroeste do Estado do Rio Grande do Sul.

***** Enfermeira. Mestra em Administração pela Universidade Federal do Rio Grande do Sul. Professora do Departamento de Ciências da Saúde da Universidade Regional do Noroeste do Estado do Rio Grande do Sul.

**:**** Enfermeira. Mestra em Educação nas Ciências pela Universidade Regional do Noroeste do Estado do Rio Grande do Sul. Professora do Departamento de Ciências da Saúde da Universidade Regional do Noroeste do Estado do Rio Grande do Sul.

******** Enfermeira da Equipe Matricial vinculada à Coordenação Municipal de Saúde Mental da Secretaria Municipal de Saúde de Ijuí - RS. Mestra em Educação nas Ciências pela Universidade Regional do Noroeste do Estado do Rio Grande do Sul.

1 Artigo produzido a partir de resultados do trabalho de conclusão do curso de Enfermagem da Universidade Regional do Noroeste do Estado do Rio Grande do Sul.

$\hookrightarrow$ Recebido em fevereiro de 2009 - Avaliado em março de 2009.

$\longrightarrow$ doi:10.5335/rbceh.2009.025 


\section{Introdução}

A doença de Alzheimer (DA) é insidiosa, crônica e com características degenerativas, marcadas pelo envelhecimento prematuro do cérebro, cujos primeiros sinais aparecem em meados da vida adulta, com frequência, progredindo rapidamente para a perda das funções mentais. (GUYTON; HALL, 2002).

Esta enfermidade é considerada a principal demência da terceira idade, perfazendo $50 \%$ de todos os tipos de demência. Surge geralmente entre os setenta e oitenta anos, podendo em alguns casos se manifestar precocemente, ou seja, após os 65 anos. A demência é considerada um conjunto de sintomas que inclui a perda progressiva e gradual das funções cognitivas, comportamentais, declínio da capacidade de raciocínio e julgamento, além da presença de depressão. (PASCALE, 2002).

Conforme Ramos e Macedo (2000), geralmente os sintomas iniciais de demência passam despercebidos; por isso, somente na fase mais avançada da doença é que a família e pessoas próximas observam o declínio cognitivo. Stuart e Laraia (2001) pontuam que as causas da DA ainda são pouco conhecidas, mas diversos fatores de risco são citados como contribuintes para o surgimento da patologia, tal como a idade, tendo em vista que é uma doença comum na terceira idade, com incidência maior em mulheres.

Comumente, a família é a primeira a perceber os sinais de alterações na saúde de seus membros, como também a primeira a realizar o cuidado, uma vez que o desequilíbrio na saúde do indivíduo afeta não somente a ele, mas também a dinâmica da família, podendo desencadear estresse e crise em sua unidade. (LUZARDO; WAIDMAN, 2004).

ADA pode ser considerada uma doença familiar por mudar profundamente $o$ cotidiano das famílias. Em estudo realizado com duas famílias que possuíam familiares com alta dependência em razão da doença, observou-se que elas estavam submetidas a uma constante carga de tensão, que as deixava exaustas, desgastadas fisica e emocionalmente, ao mesmo tempo em que apresentavam desestruturação financeira. (PELZER; FERNANDES, 1997).

Karsch (1998) menciona que as perdas das capacidades funcionais em idosos com doenças crônico-degenerativas exigem reorganização do núcleo familiar no sentido de redefinir responsabilidades e papéis, além de desarticular a dinâmica familiar e desestabilizar as relações interpessoais no cotidiano de suas vidas. No intuito de contribuir, Anderson (1998) menciona que cuidar de um idoso com DA pode ser uma das tarefas mais difíceis para a família, razão pela qual o cuidador necessita não só de informações sobre a doença e suas manifestações, mas, sobretudo, que suas limitações e inseguranças sejam conhecidas e valorizadas pela equipe de saúde.

Os efeitos negativos decorrentes da prestação de cuidados a uma pessoa com DA repercutem sobre a saúde mental e física dos cuidadores familiares, podendo desencadear um maior número de doenças psiquiátricas, utilização de drogas psicotrópicas, transtornos so- 
máticos, percepção negativa da saúde, estresse pessoal e familiar, isolamento social, sentimento de que as obrigações a cumprir com os pacientes são pesadas e geradoras de tensão. É relatada também presença de sintomas depressivos e ansiedade, em especial pelas mulheres cuidadoras. (CATTANI; GIRARDONPERLIN, 2004).

Assim, a assistência à saúde de pessoas idosas com doenças que exigem longos períodos de tratamento, as quais podem contribuir para a fragilidade tanto do sujeito doente como da família, exige dos profissionais da saúde uma abordagem que inclua a família no planejamento das ações de intervenção e no cuidado deles próprios. Contudo, Freitas et al. (2008) referem que o sistema de saúde ainda não detectou o cuidador de pessoa com Alzheimer como objeto de sua intervenção, ofertando, geralmente, atendimentos isolados e em ações direcionadas ao doente somente.

Nesse contexto, considera-se que a maior parte das famílias que conta com um de seus integrantes com DA não está preparada para lidar com as dificuldades advindas dessa vivência. Além disso, são necessárias adaptações e exigências para conviver e cuidar de uma pessoa com esta enfermidade, na perspectiva de assisti-la de forma qualificada e individualizada, resgatando e/ou preservando suas potencialidades.

Considerando o exposto, o objetivo deste estudo foi conhecer vivências dos familiares cuidadores de pessoas acometidas pela doença de Alzheimer.

\section{Percurso metodológico}

O estudo caracteriza-se como uma pesquisa qualitativa e descritiva, realizada com seis familiares-cuidadores de pessoas com doença de Alzheimer, que residem em quatro municípios da região Noroeste do estado do Rio Grande do Sul.

Dos cuidadores familiares, duas são filhas, três esposas, uma ex-esposa; cinco dos indivíduos cuidados estão vivos e um deles foi a óbito há um ano. Em relação ao período que prestam ou prestaram cuidados, varia de um a cinco anos. Buscando preservar a sua identidade, os sujeitos entrevistados foram identificados com pseudônimos de pedras preciosas: Diamante, Brilhante, Rubi, Esmeralda, Pérola e Zircônio.

A escolha dos integrantes da pesquisa deu-se por meio de indicação de pessoas que conheciam indivíduos com diagnóstico de DA e que estavam sendo ou foram cuidados por familiares. Em um primeiro momento foi feito contato telefônico, identificando-se e informando o objetivo da pesquisa. Nos casos de aceite do convite, eram marcados local e horário para a realização das entrevistas, conforme a disponibilidade de cada um.

As entrevistas aconteceram nas residências dos cuidadores, num ambiente tranquilo, confortável, livre de interrupções, no qual eles puderam falar livremente sobre o tema. É importante ressaltar que todos os familiares convidados aceitaram participar e foram receptivos com a pesquisadora que realizou a coleta de dados. Esta etapa ocorreu em novembro de 2006 e o instrumento 
utilizado foi entrevista aberta, gravada em audiotape e transcrita na íntegra.

$\mathrm{Na}$ abordagem dos cuidadores obtiveram-se também informações que possibilitaram a sua caracterização, incluindo os seguintes dados: idade, sexo, grau de parentesco, tempo de doença de seu familiar, a quanto tempo o cuida/cuidou. A questão norteadora da entrevista foi: Como é/foi para você cuidar de seu familiar com DA?

Para análise dos dados seguiram-se os passos metodológicos propostos por Minayo (2007): ordenação dos dados, classificação dos dados e análise dos dados. Foram respeitados os aspectos éticos recomendados pela resolução 196/96 do Conselho Nacional de Saúde (BRASIL, 1996), sendo o projeto de pesquisa aprovado pelo Comitê de Ética em Pesquisa da Unijuí, mediante parecer consubstanciado 151/2006.

\section{Análise e discussão dos resultados}

Da análise do conteúdo imerso nos depoimentos dos cuidadores emergiu uma categoria analítica, referente à vivência de familiares quanto às necessidades de cuidados da pessoa com DA: vivência de familiares cuidadores de pessoas com DA: o impacto da enfermidade no cotidiano da família.

As expressões dos sujeitos participantes do estudo denotaram desconhecimento em relação à doença, dificuldades de manejo com o paciente, tristeza, insegurança e falta de esclarecimento sobre a patologia por parte dos profissionais de saúde.
A DA tem início insidioso e, por isso, muitas pessoas não se dão conta de que algo está diferente em seu familiar, como esquecer a chama do fogo ligada, perder a chave, dentre outras. Normalmente, quando o familiar percebe alguma modificação no cotidiano da pessoa, já existe um comprometimento significativo.

Conforme Bigarella (1996), a DA pode ser caracterizada por perda da memória, que progride de forma irreversível, acompanhada por declínio de algumas funções cognitivas, tais como linguagem, pensamento abstrato, juízo crítico, cálculos matemáticos, habilidades para executar tarefas do cotidiano, orientação espacial, temporal e aptidão para aprender. Além dessas, podem ocorrer alterações da personalidade e sinais neurológicos. Corroborando, Marques (2001) define a fase inicial da doença como aquela em que aparecem períodos de desorientação temporal, dificuldade de evocar eventos recentes e expressar-se verbalmente, apraxia, ansiedade, negação, depressão e limitações na execução de tarefas, mesmo aquelas mais simples.

Os sujeitos deste estudo referem que, em seu familiar com DA, no início perceberam episódios de esquecimento, emergidos repentinamente, como esquecer por vezes o nome das pessoas, ou mesmo de agressividade. Esses sintomas causam prejuízos funcionais nas atividades do cotidiano, levando a família a perceber que algo não está bem.

No início ele era bem agressivo, ele já não entendia, não trabalhava. Ele começou assim a não entender o horário de sair e de voltar. (Pérola) 
Em razão das características da DA, o tempo para se estabelecer um diagnóstico clínico preciso é mais demorado, contribuindo, assim, para a insegurança e confusão do familiar, levando-a a tratar o doente de forma inadequada. A questão do desconhecimento sobre a doença também se evidencia no relato dos cuidadores.

A gente não tem conhecimento, a gente vai tendo conhecimento no desenvolver da doença. As pessoas não te esclarecem nada, não te dizem nada. Mal de Alzheimer, que vinha a ser isso? Uma gripe tu sabe o que é, mas essa doença tu não entende. (Diamante)

Tem dias que tu pensa que esse homem fica bem bom de novo, não tem nada. Mas outro dia já começa a enxergar pessoas. (Brilhante)

Nesses depoimentos se observa, de forma geral, a dificuldade que as pessoas encontram para cuidar de seu familiar mesmo no início da DA. Este fato pode ocorrer, sobretudo, pelo desconhecimento de como se manifesta, o que, por sua vez, dificulta o seu enfrentamento de forma segura. Sabe-se, ainda, que as intervenções no campo da saúde são um tanto fragmentadas, centradas na prescrição medicamentosa, com pouca ênfase nas ações educativas, em especial, direcionadas à família, ideias essas reforçadas por Luzardo e Waidman (2004) e Freitas et al. (2008).

Green (2001) colabora dizendo que a DA tem um grande impacto familiar, causando transtorno e mobilidade a todos os integrantes da família, os quais necessitam constantemente de apoio, independentemente do estágio e avanço da doença. É ela que possivelmente sofre mais com a situação, sentindo-se muitas vezes impotente diante dos fatos e sintomas apresentados pelo sujeito com a enfermidade. Conforme Smeltzer e Bare (2006), há uma enorme carga emocional colocada sobre a família do portador de Alzheimer. Na fase inicial e intermediária da doença, fisicamente ele não apresenta maiores problemas, no entanto a degeneração mental é gradual. A hostilidade/agressividade é, frequentemente, pouco entendida pelo cuidador/familiar, até que este compreenda as manifestações da doença e sua evolução.

Por outro lado, sabe-se que deve haver a preocupação por parte dos profissionais de ofertar orientações e suporte dos quais os familiares precisam. Este apoio é fundamental especialmente quando se trata de um casal de idosos em que o cônjuge, muitas vezes fragilizado, assume os cuidados do outro acometido pela doença. Nesse contexto merece destaque o planejamento de intervenções junto ao paciente acometido pela DA.

Isso aí é que deprime muito a gente, a falta de assistência. A falta de ajuda das pessoas que estudam, a falta de explicar para a gente como a gente deve agir, como lidar com essas pessoas, porque, realmente, a cada dia se torna mais difícil e não é fácil para gente suportar isso. (Diamante)

Segundo Luzardo e Waidman (2004), os profissionais da saúde não estão devidamente preparados para dar suporte à população idosa que adoece e à família que cuida. Como consequência, ocorrem conflitos, responsáveis por reações de estresse das pessoas envolvidas diretamente no cuidado, o que dificulta a 
adoção de comportamentos adequados ao enfrentamento dos agravos. Ainda de acordo com os autores, a incumbência de cuidar dos idosos, principalmente dos acometidos por doenças crônicas degenerativas, fica sob o encargo da família, causando dessa forma um enorme desgaste ao cuidador.

Geralmente, a função de cuidador é assumida somente por um membro da família, num processo que se dá mediante uma ordem natural do convívio cotidiano, relacionada com grau de parentesco, no qual os cônjuges estão em primeiro lugar; em segundo vêm filhos e genros, ou seja, quanto mais próxima for a relação familiar, maior será a responsabilidade de cuidar. Na maioria das vezes, $o$ papel de cuidar é atribuído à mulher e, culturalmente, a sociedade espera dela essa atitude. Segundo Karsch (1998), para cuidadoras esposas o ato de cuidar é inerente ao seu papel de mulher casada, em razão do compromisso assumido e selado no matrimônio.

$\mathrm{O}$ familiar/cuidador de um doente de Alzheimer torna-se a pessoa de referência para esse sujeito, dependente para a realização de suas tarefas diárias, incluindo alimentação, higiene, vestirse, andar, as quais gradativamente se complexificam. Na maioria das vezes esses cuidados se tornam difíceis pela inexperiência do cuidador em atender às demandas que vão surgindo no decorrer do tempo e que antes eram desempenhadas pela própria pessoa. Nos depoimentos de Pérola e de Zircônio percebe-se que os cuidadores se sentem sobrecarregados pelas necessidades de cuidados.
É um nenê que tem que estar cuidando, cuidando cada instante, mudando [...]. É complicado, mas é uma criança que a gente cuida. A gente viveu tantos anos juntos, a gente tem um dó dele, que quanto mais a gente faz para ele, mais tem que fazer. (Pérola).

Eu via a mãe deixando de fazer as coisas, com esse calor, ficando ali embaixo, correndo para cima e para baixo. A mãe perdia as pernas, atendia lá, atendia aqui, botava a sonda. A mãe corria lá, ver se tava pingando. Mesmo que eu tivesse lá, a mãe ia se certificar. A mãe não confiava em ninguém sem ser ela. (Zircônio)

Alterações de sono ocorrem frequentemente na DA, especialmente a inversão no ciclo de vigília, sono ou insônia noturna. As falas revelam tal comportamento.

Olha, está simplesmente horrível aqui, e de noite então, tem umas gotas que o doutor receitou daí ele dorme mais ou menos. (Rubi)

Tem noites que ele não consegue dormir, de tarde também. Ele fica assim acordado, acordado, olhando pessoas, crianças. (Brilhante)

Conforme Green (2001, p. 143), “o distúrbio do sono ocorre em mais da metade dos pacientes com Alzheimer" e a insônia apresentada pelos portadores é "um dos sintomas comportamentais mais perturbadores associados a DA, criando exaustão e desespero entre os cuidadores". Com frequência, esse é um motivo que acarreta ao cuidador expressivo cansaço físico e mental.

Outro fator que fica evidente neste estudo em relação aos distúrbios neurovegetativos "engloba um conjunto heterogêneo de alterações que incluem transtornos do ciclo vigília-sono [...], 
mudança do hábito alimentar [...], alteração do comportamento sexual e incontinência urinária ou fecal". (ALMEIDA, 1997, p. 156).

Uma vez ele urinou nove vezes por noite. Era bastante frio, aquela vez eu não sabia mais o que fazer de tanto que ele fez xixi. (Brilhante)

Desde abril já estava na fralda, tinha que usar fralda, que nem uma criança, trocar a fralda, ele não sabia mais pedir. (Pérola).

Segundo Alvarez (2001), a dificuldade com as eliminações fisiológicas é significativa para a pessoa que cuida, por se tratar da incapacidade física do doente de controlar suas eliminações, exigindo grande esforço do cuidador. Percebe-se que, apesar de ele ter compreensão da importância da higiene para a doente, a dificuldade para realizar tal tarefa torna-se estressante no seu cotidiano.

Ele não quer ninguém para dar banho pra ele. O que estou sofrendo. Quer tomar banho, mas não quer se molhar. (Rubi)

Assim banho, tem que dar banho que nem uma criança ultimamente. (Pérola)

O familiar/cuidador torna-se a pessoa mais importante para o portador de Alzheimer, responsável pelo seu bem-estar. Ele necessita estar atento às principais necessidades, tais como frio, calor e fome, pelo fato de a doença comprometer a capacidade funcional dos doentes para o desempenho das atividades da vida diária. O cuidado com a alimentação é um momento que exige dedicação e empenho do cuidador, conforme se percebe no depoimento de Pérola:
Tem que ficar sentado ao lado cuidando dele na hora do almoço, no jantar [...] Ele não sabe mais pedir nada. Se a gente não oferecer nada a ele o dia inteiro, não pede uma água para tomar. A gente tem que calcular e servir água, lanche, fruta. Tem que descascar fruta, colocar num pratinho e daí ir alcançando para ele os pedacinhos. (Pérola)

Outra questão que emergiu dos depoimentos dos cuidadores sujeitos da pesquisa foi a agressividade que os doentes de Alzheimer apresentam, associado à instabilidade de humor e agitação psicomotora.

Nervoso, esses dias me atirou aqui na cozinha assim para trás, machuquei tudo e aí quando ele fica nervoso. Antes ele não era, mas agora sim, está ficando mais agressivo, todos os dias mais, não sei por que isso está acontecendo. Ele mexe, mexe, ele não tem sossego um segundo. O que ele já estragou coisas aqui. Ele sempre trabalhou. Agora ele quer fazer tudo, mas tudo o que ele pega ele estraga. (Rubi)

Conforme Marques (2001), os episódios de agressividade são comuns durante a progressão da DA e, à medida que o paciente piora, tendem a ficar mais frequentes. Esse fato pode ocasionar ao familiar/cuidador sentimentos de angústia e insegurança. Almeida (1997) contribui ao afirmar que o comportamento ríspido ou agressivo tem um percentual considerável em pacientes com DA (cerca de 20-65\% dos casos), contudo é raro ocorrerem agressões físicas. Normalmente, o comportamento agressivo está relacionado à presença de sintomas psicóticos.

As alucinações e delírios são comuns e frequentes na DA, com início na segunda fase ou estágio intermediário, princi- 
palmente alucinações visuais, auditivas e delírios, descritos por Pérola:

Teve algum momento que dizia ver pessoas [… Ele dizia: "Meu pai já foi, minha irmã já foi" [...]. A gente estava arrumando a churrasqueira. Ele dizia: "Meu pai vem almoçar hoje" (já é falecido). Domingo ele inventou que tinha que ir lá no pai dele. (Pérola)

Nesse sentido, Sadock e Sadock (2007) pontuam que o delírio é uma ideia que não confere com a realidade externa, porém para quem o vivencia constitui-se em uma ideia real e concreta. Colaborando com os autores e após a realização das entrevistas, fica evidente que, à medida que a DA evolui, emergem pensamentos delirantes e alucinações, tal como o paciente acreditar que um dos pais ou outro familiar próximo que já tenha morrido está vivo e convivendo com ele. Esse fato também pode ocorrer pela perda da memória recente.

Outro fator agravante para o cuidado e a convivência com a pessoa com DA é a dificuldade na comunicação, que apresenta diversas manifestações ao longo de sua evolução. São frases inacabadas, ideias repetidas, dificuldades para nomear e, ao final, o mutismo.

Ele assim, ele fala pouco, a gente não entende mais o que ele fala. Daí ele fica brabo, diz que a gente não entende. Eu não entendo mesmo, nem os filhos. Ele fala umas palavras, tem que ficar horas pensando o que ele falou. Aí ele fica muito nervoso, diz que nós não queríamos atender mais ele. (Rubi)

Para Caovilla e Canineu (2002), comunicação é um processo complexo que pode ser explicado como a forma de transmitir e/ou receber mensagem. Nesse contexto, comunicar-se com uma pessoa com DA é uma tarefa difícil. Na maioria das vezes as pessoas encontram dificuldade para entender o que esse indivíduo quer dizer e não encontra palavras para expressar seus pensamentos. Sua memória se remete ao passado, ele não consegue se lembrar de fatos recentes e tem dificuldade para reconhecer pessoas, características essas relacionadas ao comprometimento da memória recente.

Aí eu sentei na frente, passei a mão na testa dela e disse: "Mãe, olhe bem firme pra mim, a senhora não está me reconhecendo? Eu sou a [...], sua filha [...]". (Esmeralda)

Às vezes pensa coisas dos antigos, antigas coisas, e às vezes não se lembra do meu nome. Muitas vezes não conhece os filhos, às vezes ele pergunta para a T.: "Quem é que tu és?" (nossa filha). O M. também, ele diz assim: "Tu é nosso filho?" (Brilhante)

As intervenções ambientais deverão ser adaptadas às necessidades específicas da pessoa com DA. O ambiente ideal caracteriza-se pela diminuição do estresse e disponibilidade de local para deambulação, com espaço e segurança. Recomenda-se um ambiente com luz suave, mas com iluminação suficiente para enxergar os móveis. Nos banheiros são recomendáveis barras de segurança e remoção de tapetes, evitando, assim, quedas e fraturas. É importante evitar músicas e dispositivos barulhentos para minimizar perturbações, além de espelhos, pois ele pode não se reconhecer mais. Do mesmo modo, mudanças na localização de móveis não são recomendadas em razão da dificuldade do sujeito de localizar-se, mesmo em espaços conhecidos. Nesse sentido, as modificações 
necessárias para uma boa qualidade de vida deverão ser feitas no início da descoberta da doença. Recursos para auxiliar a memória, como bilhetes, calendários, agendas, tornam-se úteis. (CAOVILLA; CANINEU, 2002).

Dentre as várias dificuldades com que o familiar cuidador se depara está a questão da divisão de tarefas. Assim, é importante que o cuidador receba apoio de outras pessoas da família, visto que a sobrecarga imposta pela execução de afazeres pode gerar desgaste físico e mental.

Na evolução da doença, os portadores da DA vão regredindo gradativamente, tornam-se totalmente dependentes e com comportamento pueril, como evidenciado na fala de Pérola:

Despejava a sacola de brinquedo e, às vezes, queria fazer alguma coisa, botava ele com os brinquedos. Ficava entretido com os brinquedos. Ele tinha ciúmes de pegarem a sacola de brinquedos dele. Ali ficava brincando. (Pérola)

Diante disso, torna-se relevante que o cuidador perceba a necessidade de cuidar de sua saúde também, de continuar a sua vida da melhor forma possível. Necessita cuidar de si mesmo, ter momentos de lazer, enfim, manter sua saúde física e mental. Os cuidadores muitas vezes desconhecem que podem buscar ajuda de profissionais da saúde, orientações e apoio para o desempenho das atividades. $\mathrm{O}$ enfermeiro inserido no campo da saúde hospitalar ou ambulatorial pode proporcionar suporte às famílias que possuem em seus domicílios pessoas com DA. Por meio de informações e visitas domiciliárias podem ser identificadas as necessidades que os cuidadores enfrentam durante o longo período de doença e, assim, proporcionar uma melhor qualidade de vida aos cuidadores e ao doente. Enfim, há necessidade de uma abordagem que inclua a família no planejamento do cuidado ao idoso com DA.

\section{Considerações Finais}

O estudo permitiu revelar o cotidiano dos familiares/cuidadores que convivem com portadores da doença de Alzheimer, explicitando as dificuldades por eles vivenciadas no dia a dia. É possível evidenciar que há necessidades de cuidados do familiar que acompanha o portador da $\mathrm{DA}$, visto que, à medida que a enfermidade evolui, as demandas aumentam.

Os sujeitos deste estudo referem que, inicialmente, perceberam em seu familiar com DA episódios de esquecimento que surgiram repentinamente, como não conseguir nomear as pessoas, e episódios de agressividade. A partir do momento em que essas alterações se tornaram mais frequentes, eles perceberam que algo não estava bem.

Em razão do tempo para estabelecer um diagnóstico clínico preciso da doença, surgem a insegurança e confusão do familiar, levando a que o indivíduo com DA, por vezes, seja tratado inadequadamente. No decorrer das entrevistas observaram-se nos familiares o desconhecimento em relação à doença e a dificuldade que encontram para obter informações que possibilitem o entendimento e o enfrentamento da enfermidade. 
A sobrecarga física, emocional e socioeconômica decorrente do cuidado de um familiar com DA é significativa. Assim, é fundamental que profissionais da saúde proporcionem formas de ajudar tanto o paciente quanto sua família nas dificuldades cotidianas vivenciadas, no intuito de aliviar o desgaste emocional do cuidador e proporcionar uma intervenção de acordo com as demandas dos sujeitos enfermos.

Em relação à convivência dos familiares/cuidadores destacam-se, igualmente, dificuldades em conduzir a agitação, a comunicação e os déficits de lembrança, manifestações da DA que causam expressivo sofrimento ao grupo familiar, principalmente ao cuidador direto.

Em relação à comunicação, evidencia-se por meio dos relatos que a maioria dos doentes apresenta dificuldade em se expressar em razão do comprometimento da linguagem, o que contribui para que se tornem agitados e irritados quando os familiares não conseguem entendê-los. Este fato gera angústia nos familiares, exigindo deles paciência e dedicação.

Ficam claros nas falas dos sujeitos da pesquisa sentimentos de medo, ansiedade e pesar diante de uma doença incapacitante, além da insegurança quanto ao desconhecido e da impotência com a progressão e cronicidade da patologia. $\mathrm{O}$ familiar que cuida de um idoso com DA realiza um trabalho solitário e anônimo e, a partir do diagnóstico, vai aprendendo a cuidar à medida que as situações vão aparecendo.
Muitas vezes a pessoa que cuida de idosos nem sempre escolheu ser cuidador, pois a necessidade de cuidar decorre mais de uma imposição circunstancial do que de uma preferência. A figura desses cuidadores emerge de relações familiares, exigindo reestruturação na dinâmica familiar para atender às necessidades do doente de Alzheimer.

Evidencia-se que o cuidado de idosos dependentes recai, na maior parte das vezes, sobre as mulheres. A cultura praticamente estabelece que o cuidado seja indissociável das tarefas de uma esposa e, geralmente, sem a ajuda de outros membros do grupo familiar; assim, torna-seuma tarefa árdua e desgastante, acarretando que a cuidadora, frequentemente, deixe de viver a sua própria vida. Nesse contexto, é importante a sua conscientização em dedicar momentos para si, associando o lazer e o descanso.

Em síntese, a sobrecarga de cuidar um familiar com DA acarreta danos à própria saúde do cuidador/familiar. Nesse sentido, destaca-se a necessidade de implementação de políticas públicas de assistência domiciliária que incluam perspectivas de reabilitação e orientação para as atividades rotineiras. Nesse contexto, a equipe poderá assumir o papel de acompanhar essas famílias e de desenvolver ações de assistência e acompanhamento dos cuidadores e dos doentes, contribuindo, assim, para uma melhor qualidade de vida a ambos os sujeitos envolvidos: cuidador e ser cuidado. 


\section{Experiences of family caregivers of people with Alzheimer's disease}

\section{Abstract}

Alzheimer disease may be considered as a familiar disease by interfering in the quotidian of families. The search seeks to know experiences of family with Alzheimer disease. It is qualitative, descriptive, comprising six familiar caregivers who got in tauch with the sick person continuously, residents in four cities in the northwest region of Rio Grande do Sul. The data collection occurred in November 2006, through open interview, with the following guiding question: "How is/was for you to take care of your familiar Alzheimer disease?". The data analysis followed the steps recommended for thematic analysis and the ethical aspects involving studies with people were observed. The analysis of the testimonies appeared the theme: Experiences of family caregivers of people with Alzheimer's disease: the impact of the disease in everyday family. They expressed difficulties in the management of the patient, ignorance of the disease, sadness and insecurity. We can identify the need to home care by health professionals to the family caregivers of people with Alzheimer, including guidelines and support concerning the illness and care. The results of this research also show that the relatives are not element of intervention of health teams and the actions are fragmented and specific.

Key words: Aging. Alzheimer Disease. Caregivers. Family Relations.

\section{Referências}

ALMEIDA, O. P. Manejo dos distúrbios de comportamento em pacientes demenciados. In: FORLENZA, O. V.; ALMEIDA, O. P. (Org.). Depressão e demência no idoso: tratamento psicológico e farmacológico. São Paulo: Lemos Editorial, 1997. p. 153-166.

ALVARES, A. M. Tendo que cuidar: a vivência do idoso e de sua família no processo de cuidar e ser cuidado em contexto domiciliar. 2001. Tese (Doutorado em Enfermagem) Universidade Federal de Santa Catarina, Florianópolis, 2001.

ANDERSON, M. I. P. Demência. In: CALDAS, C. P. A. (Org.). Saúde do idoso: a arte de cuidar. Rio de Janeiro: UERJ, 1998. p. 84-88.

BIGARELLA, R. L. Doença de Alzheimer: avanços e perspectivas. In: HEKMAN, PRW et al. (Org.). Atualidades em geriatria. Porto Alegre: SBGG/RS, 1996. p. 8-14.

BRASIL. Ministério da Saúde. Resolução 196 / 1996 do Conselho Nacional em Saúde. Brasília: MS, 1996.

CAOVILLA, V. P.; CANINEU, P. R. Você não está sozinho São Paulo: Abraz, 2002.

CATTANI, R. B.; GIRARDON-PERLIN, N. M. O. Cuidar do idoso doente no domicílio na voz de cuidadores familiares. Revista Eletrônica de Enfermagem, Goiânia, v. 6, n. 2, p. 254-271, 2004.

FREITAS, I. C. C. et al. Convivendo com o portador de Alzheimer: perspectivas do familiar cuidador. Revista Brasileira de Enfermagem, Brasília, v. 61, n. 4, p. 508-513, 2008.

GREEN, R. C. Diagnóstico e tratamento da doença de Alzheimer e outras doenças. Rio de Janeiro: EPCU, 2001.

GUYTON, A.; HALL, J. E. Tratado de fisiologia médica. 10. ed. Rio de Janeiro: Guanabara Koogan, 2002. 
KARSCH, U. M. (Org.). Envelhecimento com dependência: revelando cuidadores. São Paulo: Educ, 1998.

LUZARDO, A. R.; WAIDMAN, B. F. Atenção ao familiar cuidador do idoso de Alzheimer. Acta Scientiarum. Health Sciences, Maringá, v. 26, n. 1, p. 135-145, jan./jun. 2004.

MARQUES, P. R. B. Doença de Alzheimer. In: PEREIRA, C. U.; ANDRADE FILHO, A. S. (Org.). Neurogeriatria. Rio de Janeiro: Revinter, 2001. p. 281-302.

MINAYO, M. C. S. et al. (Org.). Pesquisa social: teoria, método e criatividade. 22. ed. Rio de Janeiro: Vozes, 2007.

PASCALE, M. A. Ergonomia e Alzheimer: a contribuição dos fatores ambientais como recurso terapêutico nos cuidados de idosos portadores da demência do tipo Alzheimer. 2002. Disponível em: <www.Alzheimer.med. br/cuidador.htm>. Acesso em: 12 nov. 2006.

PELZER, M. T.; FERNANDES, M. R. Apoiando a família que cuida de seu familiar idoso com demência. Texto \& Contexto em Enfermagem, Florianópolis, v. 6, n. 2, p. 339-344, 1997.

RAMOS L. R.; MACEDO M. B. Como diagnosticar e tratar: distúrbios da memória e demência. Revista Brasileira de Medicina, $x x$, v. 57 , n. 12 , p. $29-37,2000$.

SADOCK, J. S.; SADOCK, V. A. Compêndio de psiquiatria: ciências do comportamento e psiquiatria clínica. 9. ed. Porto Alegre: Artes Médicas, 2007.

SMELTZER, C. S.; BARE, G. B. Brunner \& Suddarth: tratado de enfermagem médicocirúrgica. Trad. de Carolina S. Motta et al. 9. ed. Rio de Janeiro: Guanabara Koogan, 2006.

STUART, G. W.; LARAIA M. T. Enfermagem psiquiátrica: princípios e prática. 6. ed. Porto Alegre: Artmed, 2001. 